\title{
CIUDADANOS, ELECTORES, REPRESENTANTES: DISCURSOS DE INCLUSIÓN Y EXCLUSIÓN POLÍTICAS EN PERÚ Y ECUADOR (1860-1870)
}

\section{CITIZENS, ELECTORS AND REPRESENTATIVES: SPEECHES ON POLITICAL INCLUSION AND EXCLUSION IN PERU AND ECUADOR (1860-1870)}

\author{
Oriol Luján \\ Universitat Autònoma de Barcelona
}

Recensión de / Review of: Marta Fernández Peña, Ciudadanos, electores, representantes: Discursos de inclusión y exclusión politicas en Perú y Ecuador (1860-1870), Universitat de València, Valencia, 2020, 428 páginas.

Palabras clave: Liberalismo político - Parlamentarismo - Perú - Ecuador - Siglo XIX

Key Words: Political Liberalism - Parliamentarism - Peru - Ecuador - 19th century

En los últimos años los estudios sobre parlamentarismo y representación politica han tenido un auge considerable, con una renovación de metodologías y áreas de interés que se ha añadido a la ya prolífica y consolidada trayectoria de campos como el de las elites políticas y el poder. Desde miradas y disciplinas variadas, con una valiosa incidencia de los estudios culturales, se han abierto nuevas e interesantes perspectivas de investigación.

Marta Fernández Peña se suma a dicha revitalización de los estudios parlamentarios desde una mirada cultural. El libro es resultado de una tesis doctoral dirigida por María Sierra, que ya cuenta con el reconocimiento de un accésit en el XI Premio Miguel Artola para Tesis Doctorales en Historia Contemporánea de la Asociación de Historia Contemporánea (2019). La contribución compara los sistemas politicos y representativos de Perú y Ecuador en la década de 1860 como países fronterizos con valores culturales compartidos. Y lo hace combinando el análisis de la legislación más destacada con el examen de los discursos de los representantes politicos. El principal objetivo es reflexionar sobre el valor y significado otorgado a la representación política desde las peculiaridades del liberalismo latinoamericano. Se presenta, pues, para cubrir un vacio historiográfico nada despreciable. Como recientemente ha puesto de relieve Jorge Luengo en un artículo sobre el valor de los parlamentos en el mundo hispánico durante la época de las revoluciones, "scholarship has neglected the role of parliaments in the process of independence and the consolidation of republics in the new worlds" 1 .

1 Jorge Luengo, "Flows of sovereignty: A transnational approach to parliaments in the Hispanic world during the age of revolutions", Diasporas, n 34, 2019, pp. 47-63. 
En efecto, tal vez uno de los mayores méritos del texto de Fernández Peña sea el de contribuir a cubrir un vacío historiográfico, situando en el centro del debate científico cuestiones relacionadas con la representación parlamentaria desde una mirada cultural. Así, la autora pone en valor el significado de conceptos como el de representación, parlamentarismo, ciudadano o libertad, y la cosmovisión política derivada de los mismos, en esos momentos de consolidación del liberalismo hispanoamericano. A ello dedica el segundo bloque del libro, copando la mayor atención narrativa, precedido por un bloque introductorio centrado en las estructuras básicas de poder de ambos países.

Es ilustrativa de esta temática principal la reflexión acerca de los electores y los elegibles. No sobresale por el repaso de un discurso ya asentado sobre el principio de la distinción y la capacidad, sino por ofrecer una mirada contextualizada en los casos analizados, que destacaba también por la selección de los votantes mediante el tamiz de la alfabetización y de los diputados a través de su arraigo territorial. Así, por ejemplo, es interesante ver como en Ecuador la propiedad, la renta o la profesión no se presentaban como restricción de acceso al voto, dado que el "criterio de la alfabetización en torno al derecho a la ciudadanía ya actuaba como cortapisa a la participación política de un gran número de población"2.

Menos transitados han sido aún los márgenes de la ciudadanía politica, que se presentan con una reflexión alrededor de los desarraigados, los dependientes y los incapaces. Más allá de la ya estimulante definición de esos colectivos gracias al repaso de la mirada de las elites con sus discursos y de la legislación vigente, la autora explora las posibilidades de participación de estos colectivos y las distintas estrategias utilizadas para incidir en la politica. Entre ellas, la prensa, el derecho de asociación, el derecho de petición o incluso la participación en las barras de los parlamentos con burlas, insultos, amenazas, aplausos o silbidos. Tiene el mérito, pues, de indicar posibles vías de investigación.

No menos inspiradora es la tercera parte, que cierra la investigación y que está dedicada a las transferencias e influencias ideológicas en el espacio atlántico. Destaca, por su conexión con las anteriores partes del libro, la reflexión sobre la circulación de modelos y referentes políticos entre la Europa liberal y América.

Esta investigación, con todo, se perfeccionaría cuando menos con la incorporación de un par de perspectivas. En primer lugar, con un mayor desarrollo y reflexión de algunos de los conceptos clave para el objetivo del texto, que no es otro que el análisis de los modelos de representación política en Perú y Ecuador. Así, el lector tiene la sensación de que a veces se despachan con premura cuestiones cruciales, que con más tratamiento podrian haber significado contribuciones muy valiosas. Sirva de ejemplo la noción de parlamentarismo, que la autora destaca como lugar de protección de la moral pública, la integridad y la honradez y que le permite ubicarlo como un nuevo espacio sagrado ${ }^{3}$. Al lector le quedan ganas de saber más y encontrar una reflexión más extensa acerca de este y de otros conceptos que permitan entrelazarse con las investigaciones más recientes que han trabajado sobre el significado del parlamento, ya sea en Europa o en Iberoamérica.

2 Marta Fernández Peña, Ciudadanos, electores, representantes: Discursos de inclusión y exclusión politicas en Perú y Ecuador (1860-1870), Universitat de València, Valencia, 2020, p. 248.

3 Ibid., pp. 83-84. 
Lo mismo sirve para el papel que hubiera jugado la violencia en el espacio político. La autora intuye su posible función como herramienta de contestación social y política ${ }^{4}$, de afirmación ciudadana, al fin y al cabo. Sin embargo, no se aprovecha la problemática para traer a colación una reflexión más profunda, apoyada con algunas de las aportaciones que recién han trabajado el significado de la politización mediada por la violencia.

En segundo lugar, y aunque se introducen matices ideológicos en algunos aspectos como el valor de la propiedad o la tolerancia religiosa, la tónica dominante es la introducción de una excesiva homogeneización del discurso. Es decir, se presenta un modelo demasiado uniforme, sin matizar diferencias ideológicas en el entendimiento de la representación, los elegibles, las elecciones, la libertad y otras tantas derivadas.

A menudo, el dominio de los liberales conservadores como fuerza principal de gobierno en muchas latitudes, y particularmente en España, ha llevado a asociar dichas etapas como periodos de estabilización y modernización del estado, con proyectos definidos y coherentes, en oposición a otros periodos revolucionarios, que se vinculan a la inestabilidad e incoherencia. Y tal vez el libro aquí reseñado no ha puesto suficientemente en duda dicha perspectiva, al pensar y definir la cosmovisión derivada del sistema representativo analizado únicamente a partir de un modelo y de una legislación aprobada en una década, la de 1860, dominada por conservadores. El problema es que se desprende una asociación del pensamiento politico predominante -el conservador- a la realidad de todo el liberalismo.

La distinción que introduce en los primeros capítulos del libro entre tendencias ideológicas que se establecen en la segunda mitad del siglo XIX en América Latina, luego no encuentra eco en el análisis del modelo político y representativo. Así lo ponen en evidencia afirmaciones como "de alguna manera, para poder garantizar las libertades era necesario poner orden. En este sentido, libertad, orden y ley formaban por igual parte del imaginario político de las élites latinoamericanas. A pesar de su aparente carácter antagónico, libertad y orden iban siempre de la mano en la cultura política del liberalismo"5. Si bien hasta cierto punto es indiscutible una cierta transversalidad en la aceptación de dicha visión, se echa en falta una mayor distinción de posicionamientos en el entendimiento de la libertad y de su relación con la ley y el orden. Sin ir más lejos, autores como Pablo Whipple han demostrado cómo los debates vinculados a la defensa libre en el Perú de mediados del siglo XIX permitian ensanchar las libertades individuales más allá de la visión elitista dominante ${ }^{6}$.

Enviado el (Submission Date): 19/01/2021

Aceptado el (Acceptance Date): 6/03/2021

\footnotetext{
4 Ibid., pp. 119 y 167, por ejemplo.

5 Ibid., p. 158.

6 Pablo Whipple, "Guerra a los abogados: La defensa libre y los debates sobre el monopolio de los abogados y la corrupción de la justicia peruana, 1841-1862”, en Christoph Rosenmüller y Stephan Ruderer (eds.), 'Dádivas, dones y dineros': Aportes a una nueva historia de la corrupción en América Latina desde el Imperio española a la modernidad, Madrid, Iberoamericana Vervuert, 2016, pp. 127-146.
} 